\title{
Normative annual changes in left ventricular volumes, mass and function among healthy adults: a prospective cardiac magnetic resonance imaging study
}

\author{
William E Moody ${ }^{1,2^{*}}$, Nicola C Edwards ${ }^{1,2}$, Colin D Chue ${ }^{1,2}$, Robin J Taylor ${ }^{1,2}$, Andrew You Kuan Li ${ }^{1}$, \\ Charles J Ferro ${ }^{1,3}$, John N Townend ${ }^{1,2}$, Richard P Steeds ${ }^{1,2}$
}

From 17th Annual SCMR Scientific Sessions

New Orleans, LA, USA. 16-19 January 2014

\section{Background}

Cardiac magnetic resonance imaging (CMR) is routinely performed to monitor progression and response to interventions in congenital and acquired heart diseases. Cross-sectional CMR studies report normalized reference ranges for cardiac parameters according to age decile together with assessments of short-term inter-study variability; however, most clinical imaging is repeated at much greater intervals of time. There are no prospective CMR data defining long-term changes in cardiac structure and function among healthy subjects. Without such data, it is difficult to determine whether serial changes in cardiac parameters observed in patients reflect disease progression or are merely the consequence of normal ageing. We examined the "within patient" changes in left ventricular (LV) volumes, mass and function over 12 months in a well-characterized cohort of healthy adults.

\section{Methods}

We identified 21 healthy controls (age $39 \pm 13$ yr, male $71 \%$ ) who did not proceed to uni-nephrectomy after recruitment into an observational study assessing the cardiovascular effects of live kidney donation (NCT01028703). All subjects were asymptomatic and had a 10-year risk of a cardiovascular event of $<20 \%$ (QRISK-2), a normal stress echocardiogram and normal haematology and biochemistry profiles. Exclusion criteria included: any history of cardiovascular disease, including hypertension; diabetes; glucose intolerance;

'Birmingham Cardio-Renal Group, University of Birmingham, Birmingham, UK Full list of author information is available at the end of the article chronic kidney disease; first degree relative with a proven or potentially inheritable cardiac condition. Subjects underwent CMR imaging (1.5T Magnetom Avanto, Siemens) at baseline and 12 months. Analysis of SSFP images was performed offline (Argus Software, Siemens) by a single blinded observer (W.E.M.) for assessment of LV volumes, systolic function and mass. Baseline studies were repeat analyzed by the same trained observer to assess intra-observer variability. A subset of participants underwent repeat imaging within 1 hour to determine inter-study variability.

\section{Results}

There were no significant changes in any LV parameter indexed to body surface area at 12 months (Table 1). There was however, a borderline significant reduction in absolute LV mass $(p=0.04)$. This finding is supported by existing CMR data which describe reductions in LV mass associated with advancing age. It may in part also reflect the "Hawthorne effect", whereby participants adopt healthier lifestyle behaviours in reaction to being observed. For all other LV parameters, short-term interstudy biases were comparable to any mean differences observed at 12 months (Tables 1 and 2).

\section{Conclusions}

These data have particular importance for both clinical practice and observational research: for patients undergoing annual CMR, changes in LV structure and function can be largely attributed to disease progression rather than ageing. 
Table 1 Annual change in left ventricular volumes, mass and function in healthy adult subjects

\begin{tabular}{ccccc}
\hline Parameter & Month $\mathbf{0}$ & Month 12 & Mean difference & p \\
\hline LVEF $(\%)$ & $69.4 \pm 7.8$ & $70.4 \pm 6.8$ & $1.1 \pm 3.5$ & 0.25 \\
\hline LVEDV $(\mathrm{mL})$ & $136.0 \pm 27.8$ & $136.3 \pm 23.4$ & $0.3 \pm 10.9$ & 0.91 \\
\hline LVEDVI $(\mathrm{mL} / \mathrm{m} 2)$ & $70.2 \pm 16.5$ & $70.2 \pm 13.2$ & $-0.03 \pm 6.0$ & 0.99 \\
\hline LVESV $(\mathrm{mL})$ & $43.3 \pm 17.2$ & $41.3 \pm 14.1$ & $-2.0 \pm 6.8$ & 0.26 \\
\hline LVESVI $(\mathrm{mL} / \mathrm{m} 2)$ & $22.3 \pm 9.5$ & $21.3 \pm 7.2$ & $-1.0 \pm 3.8$ & 0.29 \\
\hline LVSV $(\mathrm{mL})$ & $92.9 \pm 13.7$ & $95.1 \pm 13.1$ & $2.1 \pm 8.3$ & 0.32 \\
\hline LVSVI $(\mathrm{mL} / \mathrm{m} 2)$ & $47.8 \pm 8.6$ & $48.9 \pm 7.9$ & $1.1 \pm 4.6$ & 0.37 \\
\hline LVM $(\mathrm{g})$ & $131.5 \pm 27.6$ & $126.8 \pm 27.8$ & $-4.8 \pm 8.4$ & $0.04^{*}$ \\
\hline LVMI $(\mathrm{g} / \mathrm{m} 2)$ & $67.5 \pm 14.5$ & $65.1 \pm 13.5$ & $-2.4 \pm 5.0$ & 0.07 \\
\hline
\end{tabular}

Data are mean \pm SD. Changes in LV parameters are compared using a paired Student's $t$ test. LVEF, left ventricular ejection fraction; LVEDV, left ventricular end diastolic volume; LVEDVI, left ventricular end diastolic volume index; LVESV, left ventricular end systolic volume; LVESVI, left ventricular end systolic volume index; LVSV, left ventricular stroke volume; LVSVI, left ventricular stroke volume index; LVM, left ventricular mass; LVMI, left ventricular mass index

Table 2 Intra-observer and short-term inter-study variability for left ventricular volumes, mass and function in healthy adult subjects

\begin{tabular}{ccccccc}
\hline Parameter & Variability & Bias \pm SD & $\mathbf{p}$ & LoA & CV (\%) & ICC (95\% Cl) \\
\hline LVEF (\%) & Intra-observer & $1.00 \pm 1.27$ & 0.11 & -1.48 to 3.48 & 1.8 & $0.99(0.94$ to 1.00$)$ \\
& Inter-study & $1.50 \pm 1.76$ & 0.09 & -1.95 to 4.95 & 2.4 & $0.98(0.89$ to 1.00$)$ \\
\hline LVEDV $(\mathrm{mL})$ & Intra-observer & $0.67 \pm 3.62$ & 0.67 & -6.43 to 7.77 & 2.6 & $0.99(0.95$ to 1.00$)$ \\
& Inter-study & $0.50 \pm 6.47$ & 0.86 & -12.18 to 13.18 & 4.7 & $0.98(0.85$ to 1.00$)$ \\
\hline LVESV $(\mathrm{mL})$ & Intra-observer & $-0.83 \pm 2.79$ & 0.50 & -6.30 to 4.64 & 7.0 & $0.99(0.93$ to 1.00$)$ \\
& Inter-study & $-1.33 \pm 5.00$ & 0.54 & -11.13 to 8.47 & 12.5 & $0.97(0.78$ to 1.00$)$ \\
\hline LVSV $(\mathrm{mL})$ & Intra-observer & $1.00 \pm 2.97$ & 0.45 & -4.82 to 6.82 & 3.1 & $0.98(0.85$ to 1.00$)$ \\
& Inter-study & $1.67 \pm 4.03$ & 0.36 & -6.23 to 9.57 & 4.2 & $0.96(0.74$ to 0.99$)$ \\
\hline LVM (g) & Intra-observer & $-0.33 \pm 2.16$ & 0.21 & -4.56 to 3.90 & 1.5 & $0.99(0.95$ to 1.00$)$ \\
& Inter-study & $0.00 \pm 3.03$ & 1.00 & -5.94 to 5.94 & 2.1 & $0.99(0.90$ to 1.00$)$ \\
\hline
\end{tabular}

CV, coefficient of variability; ICC, intra-class correlation coefficient; LoA, limits of agreement; LVEF, left ventricular ejection fraction; LVEDV, left ventricular end diastolic volume; LVESV, left ventricular end systolic volume; LVSV, left ventricular stroke volume; LVM, left ventricular mass.

\section{Funding}

WEM is supported by a British Heart Foundation Clinical

Research Training Fellowship.

\section{Authors' details}

'Birmingham Cardio-Renal Group, University of Birmingham, Birmingham,

UK. ${ }^{2}$ Cardiology, Queen Elizabeth Hospital Birmingham, Birmingham, UK.

${ }^{3}$ Renal, Queen Elizabeth Hospital Birmingham, Birmingham, UK.

Published: 16 January 2014

doi:10.1186/1532-429X-16-S1-P99

Cite this article as: Moody et al:: Normative annual changes in left ventricular volumes, mass and function among healthy adults: a prospective cardiac magnetic resonance imaging study. Journal of Cardiovascular Magnetic Resonance 2014 16(Suppl 1):P99.

\section{Submit your next manuscript to BioMed Central} and take full advantage of:

- Convenient online submission

- Thorough peer review

- No space constraints or color figure charges

- Immediate publication on acceptance

- Inclusion in PubMed, CAS, Scopus and Google Scholar

- Research which is freely available for redistribution 